\title{
Objective Structured Clinical Evaluation (OSCE) versus Traditional Clinical Students Achievement at Maternity Nursing: A Comparative Approach
}

\author{
Shadia A. Eldarir ${ }^{(1)}$ and Nagwa A. Abd el Hamid ${ }^{(2)}$ \\ Maternal-Newborn Health Nursing, Faculty of Nursing Cairo University, Cairo, Egypt
}

\begin{abstract}
Using the right method of evaluation plays a considerable role in getting the appropriate result and making the right judgment. Aim: the aim of the study was to compare the effectiveness of OSCE versus traditional clinical student's achievement at maternity nursing Methods: quasi experimental deign was adopted. Implementation of the OSCE was carried out on 190 students enrolled in maternity nursing course- Cairo University. Students' achievement and perspectives were investigated. Results: the results indicated that, there was high statistical significant differences between OSCE and traditional methods in the first and second trial $(p<0.016)$, and $(p<0.000)$ respectively. The highest rate of satisfaction belonged to OSCE methods of evaluation as the students reported that OSCE measured course objectives (70.6\%), enhanced teaching level (71.6\%), related theory to practice (71.6\%), increased decision making ability (70.5\%), enhanced methods of evaluation (70\%), and made exam well developed (72\%), than the traditional method. The mean score of students' opinion was (28.1 \pm 9.6).Conclusion: OSCE can be used as an appropriate method in evaluating nursing clinical skills because of various advantages such as improving students' clinical performance, preparing highly qualified and competent graduates, increasing decision making abilities and enhance teaching level.
\end{abstract}

Key Words: Evaluation, OSCE, traditional method, students' perspectives.

\section{Introduction}

Clinical skills and practice play the main roles in training different groups; the success of trainees of these fields depends on what they memorize to some extent (Casey et al. 2009). Effective and accurate clinical evaluation should be of concern to all nursing faculties and clinical instructors. There is a reasonable expectation for evaluation to be objective, fair, specific, and documented. In addition, students need to know, very clearly delineated, the specific objectives by which they are being evaluated. One type of assessment which meets these criteria is a performance based assessment. An example of a performance-based assessment is the "OSCE" (Ahmad, etal., 2009).

OSCE has been widely and increasingly used since it was developed. Studies have shown that it is an effective evaluation tool to assess practical skills. In many instances the OSCE process has been adapted to test trainees from different healthcare related disciplines (Alinier, 2009). Also this method has attracted considerable attention because of high level of reliability, creditability and objectivity, content validity of the achieved skills, fairness, creating motivation for learning, and instructors' and students' satisfaction (Chehrzad et al. 2004, Rushforth 2007, Walsh 2009, Furlong et al. 2005, Selim et al. 2012).

In nursing education principles of OSCE can also be used in a formative way to enhance skills acquisition through simulation (Alinier, 2009). Steady increase in number of students enrolled at Egyptian nursing faculties might increase the chances of malpractice that compromise patient's conditions, in addition to limited resources from clinical sites that might hinder the opportunity of student to practice on patient. Traditional clinical nursing examinations are not standardized to assess clinical competency, and clinical reasoning skills. Acquisition of critical thinking and problem solving skills among nursing students are difficult to manage with large groups of students. Furthermore, in traditional assessment method, teachers carrying out the assessment of student performance tend to give summative scores. Therefore, it is challenging to have such an objective assessment tool to comprehensively assess students' clinical competencies especially with increased students' number (Health Workforce Development, 2006). Schoening, et al., (2006) indicated that acquisition of critical thinking and problem solving skills among nursing students were unwieldy and difficult to manage with large groups of students. Also, the nurse teachers carried out the assessment of student performance giving summative scores in traditional assessment method. While in OSCE simulation, the students find learning such skills are more beneficial because there is an immediate formative feedback following an event. Simulation-based training is superior to problem based learning for the acquisition of critical assessment and management skills (Ahmad, etal., 2009). Moreover, Bartfay, et al., (2004) concluded that OSCEs can be used most effectively in nurse undergraduate curricula to assess safe practice in terms of performance of 
psychomotor skills, as well as the declarative and schematic knowledge associated with their application. OSCEs should be integrated within a curriculum in conjunction with other relevant student evaluation methods.

Furthermore, as a method of clinical skills assessment; the OSCE possesses a number of intrinsic advantages. Firstly, it can include both summative and formative components, in which a judgment or evaluation of an individual's performance is made (summative) followed by the provision of feedback, from which the student can learn (formative). Secondly, because each student is required to demonstrate specific behaviors in a simulated work environment, strict control over the clinical context is possible, while at the same time, reflecting real-life professional tasks. This control eliminates the 'luck of the draw' problem that arises when students are assessed within the 'real-world' clinical environment with actual patients as well as the risk of harm occurring to a patient (Bartfay et al 2004; Major 2005).

Moreover, students perceived OSCE scores as a true measure for essential clinical skills being evaluated, standardized, and not affected by student's personality or social relations (Pierre et al., 2004). From this it can be suggested that OSCE provide an integrated way of measuring learning outcomes in skills based learning. The OSCE sessions not only help students determining their own weaknesses, but also enable examiners to realize what the current students' are. If required additional teaching sessions can be organized to address skills that caused problems to the students during the OSCE. The use of such sessions may well be a key element to the training of better-prepared healthcare professionals (Alinier, 2009).

There is widespread use of OSCE in general nursing specialties, maternal and newborn health nursing has been slow to adopt this evaluation method and it has only recently been introduced to maternal and new born health nursing education. OSCEs are a valuable strategy to assess 'fitness to practice' at the students' expected level of clinical practice within a nursing context where the importance of accurate patient assessment is paramount.

\section{Aim of the study:}

Compare the effectiveness of OSCE versus traditional clinical student's achievement at maternity nursing.

\section{Hypothesis}

\section{Subjects and Methods}

Maternity nursing students who evaluated by OSCE will have higher clinical achievement scores than those who evaluated by traditional methods.

\section{Research Design:}

Quasi experimental research design was adopted to accomplish the stated aim.

\section{Sample}

A total sample of 190 students enrolled in maternity nursing course and attended the training program of high risk and a critical care unit was selected. Selected students were evaluated by both OSCE and traditional methods. Data collection was done twice: firstly through assessment of 100 students during the academic year 2008-2009 second semester as a first trial at critical care unit; and on 90 students during the academic year 2009-2010 first semesters as a second trail.

\section{Tools of Data collection:}

After reviewing related literature to fulfill the aim of the study, three tools were developed by the researchers and revised by the consultants. Validity of the developed tools was achieved by 5 panels of experts in the field of maternity nursing and the needed modifications were carried out. These tools were: students' assessment and evaluation (Achievements) tool which covered the three domains to give an accurate judgment on student adequacy regarding the specified course knowledge, skills and attitudes; checklist (checklists mostly developed from the checklists introduced by $\mathrm{HWD}^{(11)}$ and rated as satisfactory, unsatisfactory, and not observed); clinical Scenarios; and student perspective tool regarding OSCE system which used to assess and analyze the information about student feedback and opinion as regard.

\section{Procedure}

The data collection procedure has been done through three phases: 1) planning of OSCE scheme and putting clinical scenario phase; 2) Implementation phase; and 3) Evaluation phase.

\section{1) Planning Phase}

OSCE was performed as follows; after determining the number and kind of station based on the trained techniques and available facilities, five stations (abdominal exam, deep tendon reflex assessment, perineal care, 
lochia assessment, and static station which included: care for hyperemsis case, care for cardiac patient, data interpretation of diabetic case result, and ect.,) were implemented. The student's instructions and checklist of each station were provided. Each station (ten-minute each) aimed to test a particular clinical competence. All the students did the techniques equally at the same time and were assessed by the researcher on the basis of the checklist.

\section{2) Implementation Phase}

A total of 190 third year students at high risk area which constitute three weeks for each student enrolled the clinical area by rotation during each semester. First week was considered for orientation about the area competency, aim, methods of evaluation, student activities, caring for the patient without stress and under supervision of clinical instructors, in addition to a small lecture about OSCE system evaluation in the first day. The students were evaluated by both OSCE methods in one day and by traditional methods in another day. Immediate formative feedback was given at the end of exam.

\section{3) Evaluation Phase}

After the conduction of the exam, student's perspectives tool was distributed to be fulfilled at their own pace and oral feedback was obtained through conducting a focus group for the students.

\section{Statistical Analysis}

Collected data were coded and tabulated using personal computer. Statistical package for the social science (SPSS) version 18 was used. Regarding descriptive statistics, data was summarized using 1) the arithmetic mean as an average; 2) The standard deviation as a measure of dispersion of results around the mean; 3 ) the frequency and percentage. Furthermore, inferential statistics included the students't-test for comparison of means of 2 independent groups. Statistical significance was considered at p-value $<0.05$.

\section{A- Students' Achievements}

\section{Results}

Regarding the effectiveness of OSCE, the current study indicated that, the maternity students obtained higher mean scores in OSCE maternity exams $(26.003 \pm 2.99)$, as compared to their mean scores with traditional methods $(23.16 \pm 5.43)$ with a highly statistically significant differences $(\mathrm{p}<0.00)($ table, 1$)$ in the first trail. Also the comparison between OSCE versus traditional method of evaluation revealed higher mean OSCE scores with a high statistical significant difference in second trail $(\mathrm{p}<0.00)($ table, 1$)$.

Table (1): Comparison of Students' OSCE versus Traditional Evaluation System Mean Scores in First \& Second Trail $(\mathrm{N}=190)$.

\begin{tabular}{|c|c|c|c|c|}
\hline \multirow{2}{*}{ Item } & OSCE evaluation & Traditional evaluation & \multirow{2}{*}{$\mathrm{T}$} & $\mathrm{p}$ \\
\cline { 2 - 3 } & \multicolumn{2}{|c|}{ Mean + SD } & & \\
\hline $1^{\text {st }}$ trail & $26.003 \pm 2.99$ & $23.16 \pm 5.43$ & 3.702 & 0.00 \\
\hline $2^{\text {nd }}$ trail & $26.11 \pm 2.26$ & $24.92 \pm 2.22$ & 4.68 & 0.00 \\
\hline Total mean scores & $26.18 \pm 4.18$ & $23.69 \pm 4.44$ & 6.23 & 0.00 \\
\hline
\end{tabular}

\section{B-Students' Perspectives}

Table (2) shows the students' opinion regarding advantages of OSCE compared with the traditional method of evolution. The highest rate of satisfaction belonged to OSCE methods of evaluation as the students reported that OSCE measure course objectives (70.6\%), enhancing teaching level (71.6\%), relate theory to practice (71.6), increased decision making ability (70.5\%), enhanced methods of evaluation (70\%), require analytical questions (66.3) and makes exam well developed (72\%), than the traditional method. The mean score of students' opinion was $(28.1 \pm 9.6)$.

In relation to student's perspectives regarding OSCE preparation, table (3) revealed that preparation to OSCE was ranked as very satisfactory to satisfactory by more than one third of the students. The same rank was given to obvious preparation of OSCE by approximately half of the student's (46.3\%), time tables were available

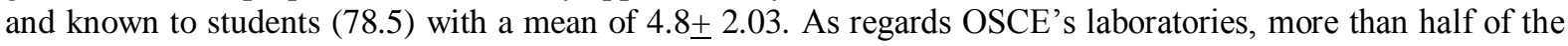
students indicated that they were suitable, lighted and ventilated, clean, calm, with availability of the needed equipments and simulators. 
Table (2): Frequency Distribution of Students' Perspectives Regarding the OSCE System

\begin{tabular}{|c|c|c|c|c|c|c|}
\hline \multirow[t]{2}{*}{ Item } & \multicolumn{2}{|c|}{ Very Satisfactory } & \multicolumn{2}{|c|}{ Satisfactory } & \multicolumn{2}{|c|}{ Unsatisfactory } \\
\hline & No & $\%$ & No & $\%$ & No & $\%$ \\
\hline 1- Measures the course objectives. & 86 & 45.3 & 48 & 25.3 & 56 & 29.5 \\
\hline 2- Is credible & 93 & 48.9 & 40 & 21.1 & 57 & 30 \\
\hline 3- Is consistent/ reliable & 81 & 42.6 & 52 & 27.4 & 57 & 30 \\
\hline 4-Requires analytical questions & 98 & 51.6 & 28 & 14.7 & 64 & 33.7 \\
\hline 5-Relates theory to practice & 102 & 53.7 & 34 & 17.9 & 54 & 28.5 \\
\hline $\begin{array}{l}\text { 6-Lead to increased decision making } \\
\text { ability }\end{array}$ & 98 & 51.6 & 36 & 18.9 & 56 & 29.5 \\
\hline 7-Increased knowledge and understanding & 90 & 47.4 & 44 & 23.2 & 56 & 29.5 \\
\hline 8-Enhances teaching level & 103 & 54.2 & 33 & 17.4 & 54 & 28.5 \\
\hline 9-Enhances methods of evaluation & 97 & 51.05 & 36 & 18.9 & 57 & 30 \\
\hline 10-Makes exams well developed & 98 & 51.6 & 39 & 20.5 & 53 & 27.9 \\
\hline 11-Makes exams/ questions clear & 81 & 42.6 & 49 & 25.8 & 60 & 31.6 \\
\hline $\begin{array}{l}\text { 12- Makes exams/ questions suitable for } \\
\text { different students levels }\end{array}$ & 79 & 41.6 & 45 & 23.7 & 66 & 34.7 \\
\hline $\begin{array}{l}\text { 13- Makes exams/ questions to cover } \\
\text { most of course contents }\end{array}$ & 80 & 42.1 & 34 & 17.9 & 76 & 40 \\
\hline
\end{tabular}

Table (3): Frequency Distribution of Student's Perspectives Regarding Preparation to OSCE and OSCE lab.

\begin{tabular}{|c|c|c|c|c|c|c|}
\hline \multirow[t]{2}{*}{ Item } & \multicolumn{2}{|c|}{ Very Satisfactory } & \multicolumn{2}{|c|}{ Satisfactory } & \multicolumn{2}{|c|}{ Unsatisfactory } \\
\hline & No. & $\%$ & No. & $\%$ & No. & $\%$ \\
\hline $\begin{array}{l}\text { Preparation for the OSCE } \\
\text { 1-Was obvious before establishing OSCE }\end{array}$ & 53 & 27.9 & 35 & 18.4 & 102 & 53.7 \\
\hline $\begin{array}{l}\text { 2- Time tables were available and known } \\
\text { to students }\end{array}$ & 33 & 17.4 & 116 & 61.1 & 41 & 21.6 \\
\hline \multirow[t]{2}{*}{$\begin{array}{l}\text { 3- Satisfaction of number of } \\
\text { exam }\end{array}$} & 31 & 16.3 & 130 & 68.4 & 29 & 15.3 \\
\hline & \multicolumn{6}{|c|}{ Mean $4.8 \pm 2.03$} \\
\hline $\begin{array}{l}\text { The OSCE labs. } \\
\text { 1-Suitable for learning }\end{array}$ & 46 & 42.2 & 46 & 24.2 & 88 & 46.5 \\
\hline 2-Lighted and ventilated & 45 & 23.7 & 55 & 28.9 & 90 & 47.4 \\
\hline 3- Clean Set up & 45 & 23.7 & 43 & 22.6 & 102 & 53.7 \\
\hline 4- Calm & 43 & 22.6 & 43 & 22.6 & 104 & 54.7 \\
\hline $\begin{array}{l}\text { 5-The needed equipments and simulators } \\
\text { are available }\end{array}$ & 41 & 21.6 & 44 & 23.2 & 105 & 55.3 \\
\hline 6-Suitable for student' number & 45 & 23.7 & 48 & 25.3 & 97 & 51 \\
\hline Mean + SD & \multicolumn{6}{|c|}{$10.2+4.2$} \\
\hline
\end{tabular}

\section{Discussion}

The acquisition of clinical skills is paramount to the development of a safe and competent practitioner (Brookes, 2007). OSCE as a performance-based assessment is a well established student's assessment tool for many reasons: competency- based, valid, practical and wise effective mean of assessing clinical skills that are fundamental to the practice of nursing and other health care related professions (Alinier, 2003).

Regarding the effectiveness of OSCE, the current study pointed out that, the comparison between OSCE versus traditional method of evaluation revealed higher mean OSCE scores with a high statistical significant difference in first trail. This finding is congruent with Smith et al., (2012) who compared different methods of assessing midwifery students' clinical skills, the results indicated that none of the assessment methods of clinical skills can provide complete information about the students' skills but OSCE method can be used as a very valuable method for assessing clinical competency of students because of appropriate reliability in comparison to methods such as worksheet, clinical observance, and etc. As well, the mean scores of students who undergone OSCE in the second trial were high as compared to the group who undergone traditional method 
of evaluation with high statistical significant difference $(\mathrm{p}<0.000)$. This is in the same line with Huang et al (2007), who studied medical students' satisfaction with OSCE method. The result showed that the majority of students were satisfied and expressed that its effect on improving clinical skills was pleasing. Also, Brosnan et al. (2006) studied the effect of using OSCE on the self-confidence of nursing students and their point of view toward clinical practice. The results showed that the students who got higher scores in OSCE assessment method had more self-confidence for doing clinical practice. Also, students mentioned that OSCE was a meaningful and the fairest method of assessing clinical skills.

In relation to the students' opinion regarding advantages of OSCE compared with the traditional methods of evaluation, they indicated that, OSCE measure course objectives, enhancing teaching level, relate theory to practice, makes exam well developed, increased decision making ability and enhanced methods of evaluation, than the traditional method. The students' opinion about the OSCE system was ranked as very satisfactory to satisfactory by more than two thirds of the students. This feedback can suggest that OSCE is an objective tool for evaluating clinical skills. These findings are in agreement with a study conducted by El Nemer \& Kandeel, (2009) who reported that most students viewed OSCE as a fair assessment tool which covered a broad area of knowledge, allowed them to compensate in some areas and minimized their chances of failing. Moreover, Nolti et al (2011) studied 58 nursing students' opinions that were assessed by OSCE. The researchers had wanted the students to express the best and worst characteristics of this exam. The results were as follows: the best specifications included the student being aware of the examiner's exact expectations, has the chance to express all aspects of his ability in performing a technique, and the student feels that everything is provided for him to express his knowledge. The worst parts included: stress and anxiety of student before the exam.

As well, in a study conducted by Turner \& Dankoski, (2008) to assess the validity, reliability and feasibility of OSCE team, the majority of students felt that they had been marked fairly. Most students provided positive feedback about the quality of OSCE performance in terms of the clarity of the instructions of the exam, the sequence of OSCE stations, the reflection of the tasks taught and the time at each station. These findings are consistent with Pierre et al. (2004) who indicted that most students viewed OSCE as comprehensive, covered a wide range of knowledge and clinical competencies and a useful practical experience. As well more than two thirds of students believed that the assessment was fair and they reported their need for more time to complete the stations. In another study done by Alinier (2003), nursing students perceived OSCE as a favorable experience that should be repeated regularly. However, Mitchell et al. (2009) mentioned that in contrast with various positive specifications of OSCE, for better usage of this method in assessing clinical skills of nursing students, it is essential that this method is used besides other methods of assessment so that more accurate and favorable results will be found for judgment.

\section{Conclusion}

Based on the findings of the results of the present study and reviewing the related studies, it can concluded that with better planning in performing OSCE and familiarizing the students with the stations and limitations of OSCE through practice during the term, stressors could be decreased. OSCE can be used as an appropriate method in evaluation nursing clinical skills because of various advantages such as improving students' clinical performance, preparing highly qualified and competent graduates, increasing decision making abilities and enhance teaching level. Therefore improving the quality of evaluation as OSCE is a valid and reliable technique uniquely capable of assessing many fundamental clinical skills that are not being assessed in a rigorous way in most undergraduate. OSCE examination offers an attractive option for evaluating practitioner competency.

\section{Recommendations:}

Based on findings of the current study, it is recommended that:

1. OSCE must be used as an integral part of the clinical evaluation system / students' assessment at the under graduate.

2. OSCE should be used as a method of evaluating clinical practice in a combination with traditional method.

3. It can be suggested that OSCE has the potential to make a very effective and meaningful contribution to 'fitness for practice'.

4. The level of competency in OSCE should be tested not only for nurses using the traditional methods of learning, but also for distance learning students.

\section{Acknowledgment:}

The authors are thankful to colleagues and the students in Faculty of Nursing Cairo University who participated in this study for their great cooperation to carry out this work. 


\section{References:}

[1] Ahmad, C., N. Ahmad \& Abu Baker R., Assessing Nursing Clinical Skills Performance Using Objective Structured Clinical Examination (OSCE) for Open Distance Learning Students in Open University Malaysia. International Conference on Information; Kuala Lumpur, (2009). 12-13 August.

[2] Alinier, G.. Nursing students' and lecturers' perspectives of OSCE, incorporating simulation(2009).

[3] Alinier, G. Nursing students' and lecturers' perspectives of objective structured clinical examination incorporating simulation. Nurse Education Today., 2003, 23(6): 419-426.

[4] Bartfay W. J., Rombough R., Howse E, \& LeBlance, R. The OSCE in nursing education: objective structured clinical examinations can be vehicles for nursing education and practice by promoting the mastery of clinical skills and decision making in controlled and safe environments. The Canadian Nurse (2004)100: 18-27.

[5] Brookes, D. Objective Structured Clinical Examination assessment. (2007) www.nursingtimes.net

[6] Brosnan, M., Evans, W., Brosnan, E. \& Brown, G., Implementing objective structured skills evaluation (OSCE) in nurse registration programmes in a centre in Ireland: A utilization focused evaluation. Nurse Education Today(2006). 26, 115-122

[7] Casey PM, Goepfert AR, Espey EL, Hammoud MM, Kaczmarczyk JM, Katz NT, N, etal.. To the point: reviews in medical education - the Objective Structured Clinical Examination. American Journal Obstetetric Gynecology; (2009)200(1): 25-34.

[8] Chehrzad MM, Shafie Pour SZ, Mirzaei M, Kazem Nejad E Comparison between two methods: Objective structured clinical evaluation (OSCE) and traditional on nursing students' satisfaction. Journal of Medical Faculty Guilan University of Medical Sciences. Summer; (2004). 13(50):8-13

[9] El-Nemer, A. \& Kandeel, N. Using OSCE as an Assessment Tool for Clinical Skills: Nursing Students' Feedback. AJBAS JulySeptember, 2009 2465-2472.

[10] Furlong E, Fox P, Lavin M, \& Collins R) Oncology nursing students' views of a modified OSCE. European Journal of Oncology Nursing 2005 (9), 351-359

[11] Health Workforce Development (HWD) Project Final report, Baseline survey- part I: Assessment of competency resulting from medical and nursing education in Egypt. Egypt Health Workforce Development Project (May 2006).

[12] Huang YS, Liu M, Huang CH, \& Liu KM. Implementation of an OSCE at Kaohsiung Medical University. Kaohsiung J Med Sci. (2007). 23(4):161-9

[13] Major, D., Seven years on the bandwagon: the progress of an objective structured clinical evaluation programme. Nurse Education Today (2005) 25, 442-454.

[14] Mitchell M L, Henderson A, Groves M, Dalton M,\& Nulty D The objective structured clinical examination (OSCE): Optimizing its value in the undergraduate nursing curriculum. Nurse Education Today; (2009) 29(4): 398-404.

[15] Nolti D, Mitchell M.L, Leffrey C.A, \& Henderson A, Groves M. Best Practice Guidelines for use of OSCEs: Maximising value for student learning. Nurse Education Today; . (2011) 31:145-151.

[16] Pierre, R., Wierenga A., Barton M., Branday J.M. \& Christie, C. Student Evaluation of an OSCE in Pediatric at the University of the West Indies, Jamaica. BMC Medical Education, (2004)4(22):1-7.

[17] Rushforth H E. Objective Structured Clinical Examination: Review Of Literature And Implication For Nursing Education (2007). Nurse education today; 27:481-490

[18] Schoening, A., Sittner, B., \& Todd, M. Simulated clinical experience: nursing students' perceptions and the educators' role (2006). Nurse Educator, 31(6), 253-258.

[19] Selim A, Ramadan F, El-Gueneidy M, Gaafer M. Using Objective Structured Clinical Examination (OSCE) in undergraduate psychiatric nursing education: Is it reliable and valid?. Nurse Education Today (2012) (32) 283-288

[20] Smith V, Muldoon K, \& Biesty L. The Objective Structured Clinical Examination (OSCE) as a strategy for assessing clinical competence in midwifery education in Ireland: A critical review. Nurse Education in Practice; . (2012). 12(5): $242-247$.

[21] Turner, J.L. \& Danksoki, M.E. Objective structured clinical exams: a critical review, Family Medicine. September (2008), 574-578

[22] Walsh m, bailey hill P, \& koren I. Objective Structure Evaluation of Clinical Competence: An Integrative Review. Journal of advanced nursing; (2009) 65(8):1584-1595. 